\title{
ASHERAH E BUDDHA TĀRĀ: UMA ASSOCIAÇÃO POSSÍVEL?
}

\author{
José Ademar Kaefer* \\ Patricia Guernelli Palazzo Tsai* ${ }^{* *}$
}

\section{RESUMO}

O presente artigo objetiva contribuir (iniciar) com a discussão acerca do aspecto feminino presente em Asherah e Tārā, trazendo como possível a associação entre ambas através de seus atributos físicos e identificação com elementos da Natureza. Ambas possuem fortes características ligadas à fertilidade e à maternidade; ambas têm em comum a iconografia da árvore, com possível associação à árvore da vida (Asherah: terebinto, carvalho e tamareira; Tärā: asoka e bodhi); ambas seguram em suas mãos flores de lótus, simbolizando o poder da criação (gerar vida) e da pertença à linhagem divina; ambas são representadas de pé e sozinhas, desacompanhadas de representação masculina; ambas foram perseguidas e colocadas à margem. Palavras-chave: Asherah; Tārā; Fertilidade; Flor de lótus; Árvore da vida.

\section{ASHERAH AND BUDDHA TĀRĀ: A POSSIBLE ASSOCIATION?}

\section{ABSTRACT}

This article aims to contribute to the discussion about the feminine aspect present in both Asherah and Tärā, identifying as plausible association between them through their physical features, as well as their identification with elements of nature. Both have strong characteristics related to fertility and maternity; both have in common the tree iconography, a possible association with the tree of life

* Doutor em Sagradas Escrituras pela Universidade de Münster, Alemanha; Pós-doutorado pelo Departamento de Arqueologia da Universidade de Tel Aviv, Israel; Professor titular de AT do Programa de Pós-graduação em Ciências da Religião - UMESP; Pesquisador FAPESP; Coordenador do grupo de pesquisa “Arqueologia do Antigo Oriente Próximo”. E-mail: jademarkaefer@ gmail.com

** Mestranda em Ciências da Religião pela Universidade Metodista de São Paulo; Bacharel em Ciências Sociais e Jurídicas pela Pontifícia Universidade Católica de Campinas. Membra do Grupo de Pesquisa Religião e Educação. E-mail: patricia.palazzo@gmail.com 
(Asherah: terebinth, oak and date palm; Tãrā: asoka and bodhi); both hold lotus flowers in their hands, symbolizing the power of creation (life-giving) and belonging to the divine lineage; both are represented standing and unattended, unaccompanied by male representation; both were persecuted and swept aside.

Keywords: Asherah; Tārā; Fertiliy; Lotus flower; Tree of life.

\section{ASHERAH Y BUDDHA TĀRĀ: ¿UNA POSIBLE ASOCIACIÓN?}

\section{RESUMEN}

Este artículo tiene como objetivo contribuir a la discusión sobre el aspecto femenino presente en Asherah y Tărā, trayendo como sea posible la asociación entre ambos a través de sus atributos físicos, así como la identificación con elementos de la naturaleza. Ambas tienen fuertes características de fertilidad y maternidad; ambas tienen en común la iconografía del árbol, con posible asociación con el árbol de la vida (Asherah: terebinto, roble y palmera datilera; Tārā: asoka y bodhi); ambas sostienen flores de loto en sus manos, simbolizando el poder de la creación (generar vida) y perteneciendo al linaje divino; ambas están representados de pie y solas, sin compañía masculina; ambas fueron perseguidas y puestas al margen.

Palabras clave: Asherah; Tārā; Fertilidad; Flor de loto; Árbol de la vida.

\section{INTRODUÇÃO}

A busca pelo conhecer do que foi experienciado pelas sociedades do passado, seus contextos, crenças, produção manual e intelectiva, é um motivador constante para expedições do saber na tentativa de formular teorias e chaves de leitura para uma melhor compreensão acerca do comportamento humano ontem e hoje. E, então, nesse processo investigativo, o pesquisador e a pesquisadora se deparam com perguntas instigantes, como por exemplo: como relacionar imagens que não pertencem ao mesmo espaço geográfico e contexto histórico, contudo apresentam grandes similitudes? É o caso da imagem de duas divindades femininas, Asherah e Buddha Tārā, cujas características análogas queremos abordar aqui.

A presente pesquisa não se propõe a fazer uma análise aprofundada acerca dos contextos relacionados às duas divindades, mas, sim, tratar das (diversas) similaridades observadas nas figuras de Asherah 
e Tārā e qual possível relação entre ambas. Arriscamo-nos a afirmar de antemão, que há indícios de que, por força de relações políticas e comerciais entre povos, mesmo de regiões distantes, seria possível que houvesse troca ou intercâmbio de símbolos e seus significados, vindo a influenciar ou a servir de inspiração para incorporar tais elementos na criação de novos arquétipos.

Sabemos que, com as invasões de Alexandre o Grande em território indiano houve trocas entre a cultura indiana e a grega (Rama TRIPATHI, 1999, p. 117-118), especialmente nas regiões da Báctria (que compreende atualmente Afeganistão, Paquistão, Uzbesquistão e Tajiquistão) e Gandhara (norte do Afeganistão, leste do Paquistão e Caxemira). Foi o que deu origem ao greco-budismo, no séc. IV a.C. e, sob essa efervescência de novidades, às primeiras representações antropomórficas do Buddha histórico.

Contudo, é provável que já antes de Alexandre Magno houvesse contato comercial e cultural entre a Mesopotâmia e o Levante e as regiões asiáticas. Com a domesticação do camelo, por volta do século X-IX a.C., que foi o meio de transporte que tornou possível o intercâmbio comercial entre os dois mundos, iniciam-se aos poucos as rotas comerciais de seda, especiarias e outros produtos. É possível que, então, mas, principalmente a partir do domínio persa, elementos característicos de Asherah pudessem ter sido assimilados, juntamente com outras interações culturais.

\section{A DEUSA ASHERAH EM CANAÃ}

O culto a Asherah foi um assunto bastante pesquisado nas últimas décadas, principalmente após a descoberta das inscrições de Kuntillet 'Ajrud (Othmar KEEL e Christoph UEHLINGER, 1992; Susan ACKERMAN, 1992; Tilde BINGER, 1997; William DEVER, 2005). Kuntillet 'Ajrud mudou o conceito de culto que se tinha em Israel e Judá até então. Na América Latina, Asherah tem tido interesse especial, principalmente a partir da hermenêutica feminista (Severino CROATTO, 2002; Monika OTTERMANN, 2006; Ana CORDEIRO, 2011; Ivoni REIMER, 2008; Sue'Hellen de MATOS, 2019). Esse particular contribuiu para uma abordagem mais ampla, para um viés mais aberto, voltado à diversidade de divindades presente em 
toda Canaã, fator que influenciou diretamente sobre as práticas religiosas do povo de Israel e Judá.

Pela grande quantidade de imagens femininas encontradas nas escavações arqueológicas, é provável que o culto às divindades femininas em Canaã fosse muito maior que o culto às divindades masculinas. Esta supremacia parece estar ligada ao atributo da fertilidade. Uma destas divindades femininas fortemente presente em Canaã é Asherah.

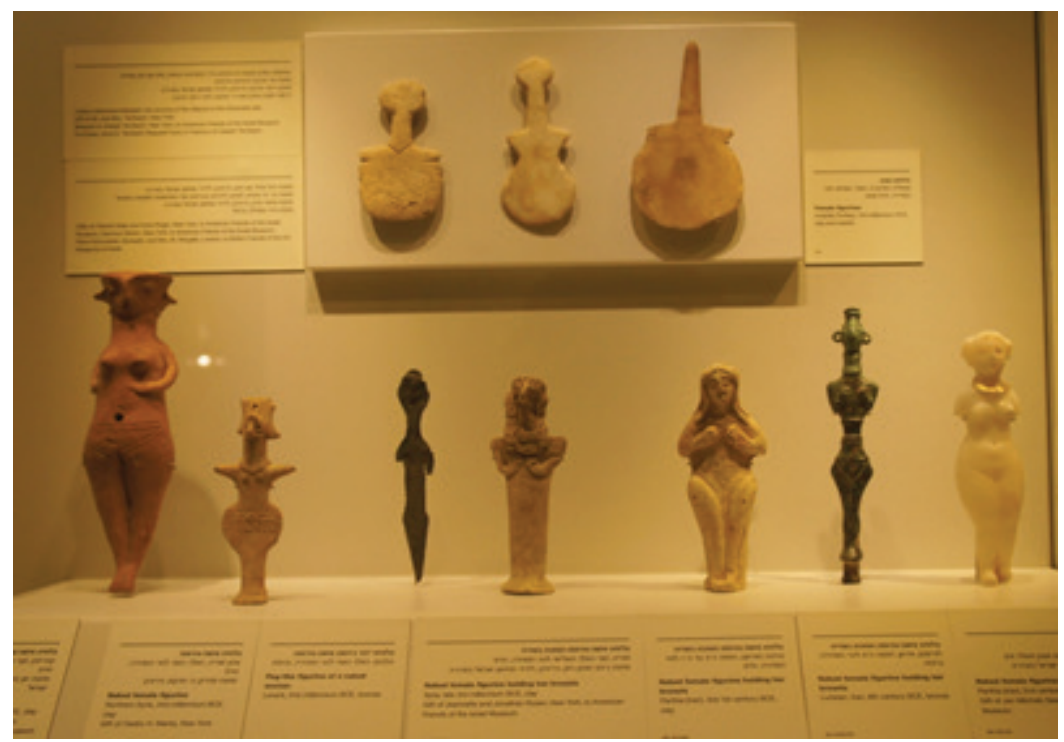

Figura 1 - Divindades femininas de Canaã (Foto: autor. Museu de Israel).

O culto a Asherah é atestado em tempos muito remotos, que adentra possivelmente ao terceiro milênio a.C. Conforme Römer, a primeira referência escrita à Asherah ocorre na Mesopotâmia, no tempo de Hamurabi, séc. XVIII a.C. Em acádio e hitita, o nome Asherah aparece como Ašratu(m), Aširatu, e Aširtu. Contudo, é nos textos ugaríticos do segundo milênio a.C., onde ela aparece com o nome 'Atirat(u)', que a menção à Asherah ocorre com maior frequência. Ali, em especial no ciclo de Baal, Asherah é mencionada como a consorte de El, como a Deusa mãe dos deuses do panteão e como aquela que amamenta seus filhos deuses (Thomas RÖMER, 2017, p. 157-158).

Abaixo se verá brevemente o debate sobre, se Asherah e 'Atirat seriam ou não a mesma divindade. 


\section{AS CARTAS DE TELL EL-AMARNA E AS DIVINDADES FEMININAS EM CANAÃ}

Uma das poucas, mas ampla, referências acerca do contexto de Canaã antes de Israel e Judá são as cartas de Tell el-Amarna (Anson RANEY, 2015). Ainda que estas façam pouca alusão a cultos na região, provavelmente para não afrontar o faraó egípcio, é possível encontrar nas entrelinhas das cartas tais alusões, em particular a divindades femininas, que é nosso objeto.

É o caso das cartas 60, 61 e 62, cujo remetente e governante de Amurru se identifica como 'Abdi-Ashirta, que no acádio significa "servo de Ashirta” (Anson RANEY, 2015, p. 418-425), Deusa que na Bíblia é associada à Asherah. Caso similar se encontra nas cartas 63, 64, 65 e 335, cujo remetente se denomina 'Abdi-Ashtart, que na língua acádia significa "servo de Ashtart” (Anson RANEY, 2015, p. 426-431; 1224-1225), Deusa, cuja característica na Bíblia também se confunde com Asherah. 'Abdi-Ashtart provavelmente foi o governante de Gat (Yuval GOREN, Israel FINKELSTEIN e Nadav NA'AMAN, 2004, p. 284). Portanto, é significativo que o reino de Amurru e a cidade de Gat, futura e poderosa capital da filisteia, fossem governados por adoradores de Asherah e Ashtart.

Outro caso a assinalar se encontra nas cartas 273 e 274 , cuja remetente é uma mulher, possível governante de Gezer ou Betshemes (GOREN, FINKELSTEIN, NA'AMAN, 2004, p. 277-279). O interessante é que esta "rainha" não diz seu nome, somente se apresenta como a "Senhora dos Leões" (Belit-neshet). Portanto, devia ser conhecida do faraó como tal. Uma mulher governanta é um caso único nas cartas de Tell el-Amarna. É possível que este nome "Senhora dos Leões" (Belit-neshet) estivesse relacionado a uma deusa da região, como Asherah ou Ashtart. Associada, talvez, à lâmina de ouro encontrada em Laquis (Amihai MAZAR, 2003, p. 271), onde está representada uma Deusa de pé sobre um cavalo e segurando flores de lótus nas mãos. Ou, ainda, ao desenho encontrado em Betshemes, que mostra uma Deusa com trajes masculinos e em pé sobre uma cesta, também segurando flores de lótus nas mãos (Leide DOS SANTOS, 2018, p. 137-146). Como visto, é possível que a "Senhora dos Leões" reinasse sobre uma destas cidades onde as figuras (Asherah?) foram encontradas. 


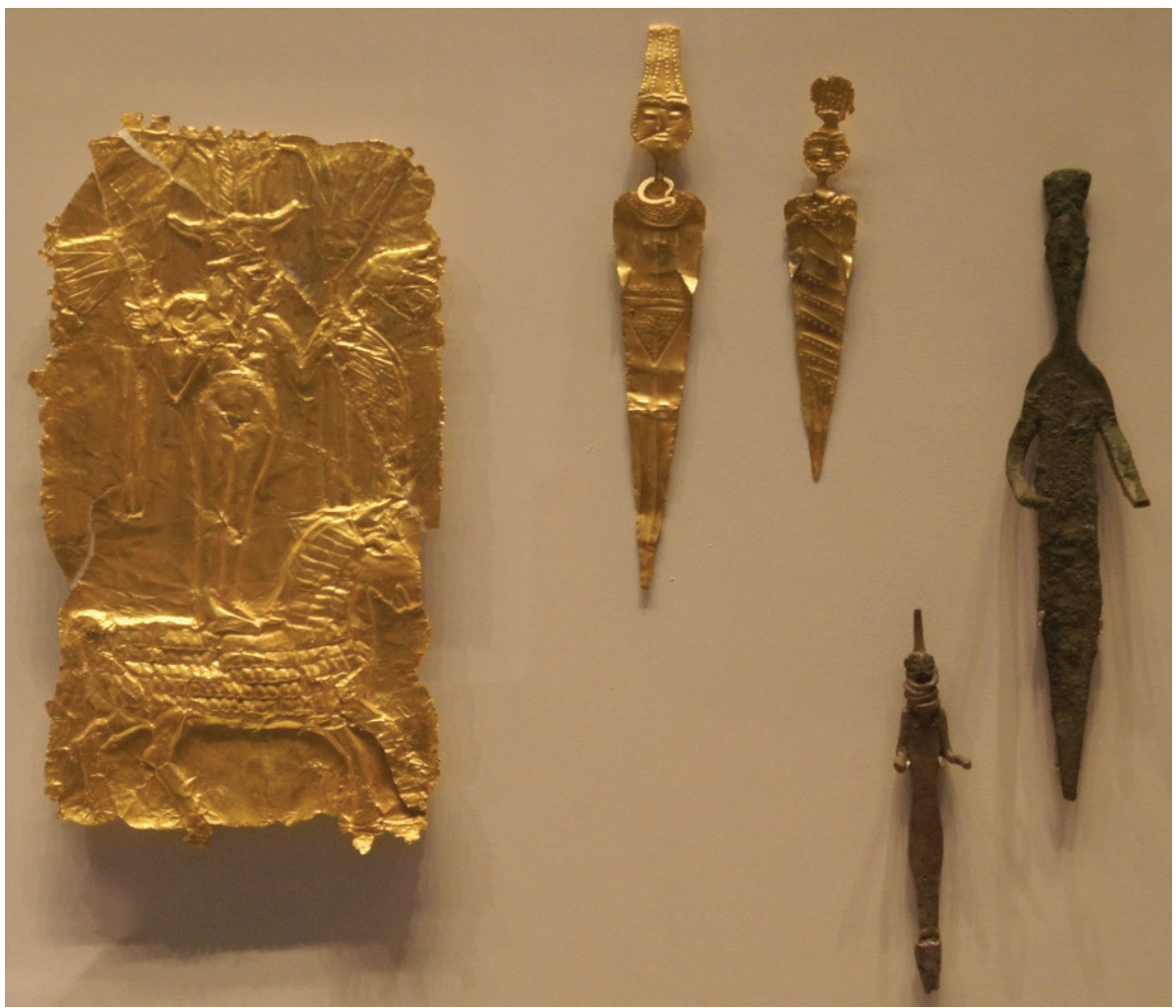

Figura 2- Lâmina de ouro encontrada em Laquis representando uma Deusa (Asherah?) com uma coroa egípcia, de pé sobre um cavalo e com flores de lótus nas mãos. Ao lado, outras divindades (Foto: autor. Museu de Israel).

Por último, convém mencionar as cartas enviadas por Rib-Hadda, governante de Biblos (EA 77, 87, 95, 102, 132). Na apresentação das cartas, o governante de Biblos envia aos destinatários a bênção da Deusa de sua cidade, a "Senhora de Biblos". O interessante é que a Deusa de Biblos é mencionada ao lado de Amon, o Deus supremo do panteão egípcio, inclusive, Rib-Hadda a chama de "a Deusa do rei, meu senhor" (EA 102,1-7). Em uma das cartas (EA 132), Rib-Hadda saúda o próprio faraó com a proteção da "Senhora de Biblos". Ou seja, a Deusa da cidade de Biblos era reconhecida pelo faraó. 


\section{ASHERAH NA BÍBLIA}

Como visto acima, nos textos ugaríticos a consorte de El era Athirat ('Atirat), a Deusa mãe. No antigo Testamento o nome Athirat, consorte de El, aparece como Asherah. Apesar de esta visão ser quase um consenso entre os/as pesquisadores/as, ela não é unânime. Os argumentos mais insistentes é de que a característica de Athirat, como consorte de El, é a maternidade, a mãe dos deuses, enquanto que a característica de Asherah do AT seria a fertilidade, a Deusa da fertilidade. Além disso, de que nos textos ugaríticos, Athirat se encontra ao lado de El, enquanto no AT a Asherah é associada a Baal. Ou ainda, que nos textos ugaríticos Athirat é relacionada ao mar, enquanto que no AT não aparece esta relação (Tilde BINGER, 1997; John DAY, 2002).

A nosso entender, esta visão se alinha com a visão do cronista (2Crônicas), pois, em geral, quando Asherah aparece no AT ela ocorre na forma singular, ${ }^{2}$ contudo, algumas vezes aparece também no plural, 'asherim, que, curiosamente, é um plural masculino. ${ }^{3}$ Esta forma ocorre na maior parte no livro de 2 Crônicas, oito vezes. Enquanto que no singular o nome ser refere à Deusa, provavelmente na imagem de uma mulher, no plural a tendência é se referir à árvore, ou a um tronco de madeira, que era outra forma de culto à Asherah, principalmente quando relacionado à fertilidade da terra. Ou seja, a tendência do cronista é apresentar Asherah não como uma Deusa, mas como um objeto de culto, um tronco de madeira. Será essa tendência do cronista intencional, para difamar a Deusa, ou será porque quando da redação dos livros de Crônicas, por volta do século III a.C., os judaítas não tinham como conceber a ideia de uma deidade feminina, uma vez que todas as outras divindades passaram a ser consideradas ídolos?

De outra parte, Asherah não é associada somente a Baal, ela também é mencionada ao lado de Javé. Em 2Rs 23, por exemplo, Asherá se encontra no templo de Jerusalém, possivelmente ao lado de Javé. Assim também, como já visto, Asherah aparece ao lado de Javé nos

Referências à Deusa Asherah na Bíblia: Ex 34,13; Dt 7,5; 12,3; 16,21; Jz 3,7; 6,25.26.28.30; 1Rs $14,15.23 ; 15,13 ; 16,33 ; 18,19 ; 2$ Rs 13,6;17,10.16; 18,4; 21,3.7; 23,4.6.7.14.15; 2Cr 14,2; 15,16; 17,6; 19,3; 24,18; 31,1; 33,3.19; 34,3.4.7; (Os 14,9); Is 17,8; 27,9; Jr 17,2; Mq 5,13.

3 Em Jz 3,7 aparece também no plural feminino (Asherot). 
escritos de Kuntillet 'Ajrud'4 e no templo javista de Arad (José KAEFER, 2015, p. 62).

Com o desenvolvimento do monoteísmo em Judá, que pelas informações bíblicas começou com o rei Josias (2Rs 22-23), o culto à Asherah foi sendo abolido e suas características assimiladas pelo javismo. Ou seja, o javismo não só se apropriou de elementos característicos de El e de Baal, mas também das divindades femininas, como de Asherah (Os 14,9). Ao atribuir características que eram próprias de Asherah a Javé, o culto à Asherah, de certa forma, continuou vivo no imaginário da população. De maneira que, práticas de culto à Asherah possam ser percebidas até períodos bem tardios na história de Judá (Ct 8,5b).

\section{ASHERAH E A FLOR DE LÓTUS}

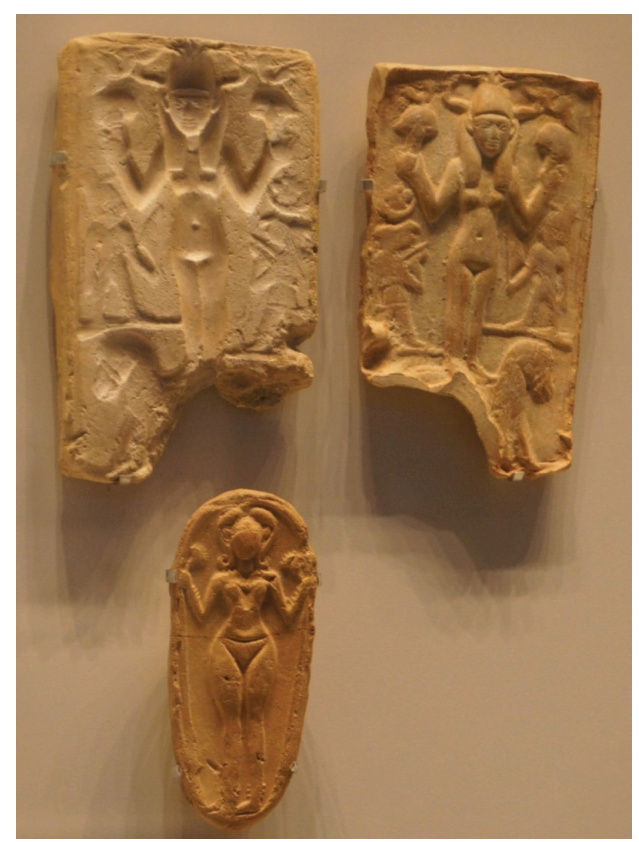

Figura 3 - Deusa Asherah com flores de lótus (Foto: autor. Museu de Israel)

4 Apesar de que há quem ateste que na referência de Kuntillet 'Ajrud trate-se do objeto de culto e não da Deusa. Um dos argumentos preponderantes em favor desta interpretação é o desenho da árvore ladeada por dois carneiros que se encontra em um dos potes de cerâmica, que se supõe referir-se à Asherah (John DAY, 2002, p. 49-52; Nadav NA'AMAN e Nurit LISSOVSKY, 2008, p. 186-208). 
As figuras acima trazem Asherah em pé, com suas formas arredondas e partes íntimas bem demarcadas, e segurando flores de lótus em ambas as mãos. É muito significativo esse particular das flores de lótus nas mãos da Deusa. A flor de lótus é uma planta aquática da família das ninfeáceas e muito comum no Egito, onde faz parte da mitologia do povo desse país.

Na Bíblia, a flor de lótus é citada no livro de Jó 40,21-22. É citada no plural masculino (șe'elym) e aparece unicamente nestes dois versos, onde Deus fala do vigor do hipopótamo (behemot) que descansa debaixo dos lótus, e os lótus lhe dão sombra. É curiosa esta referência. Por que relacionar o lótus ao hipopótamo? Parece-nos que, assim como o lótus está relacionado ao mito da criação no Egito antigo, também o hipopótamo o é. Por exemplo, acreditava-se que o rio Nilo nascia da boca de um hipopótamo, como se pode ver numa cena representada nos mosaicos na chamada "casa do festival do Nilo", que ainda pode ser vista na da antiga cidade de Séforis (José KAEFER, 2012, p. 66). A Odisseia de Homero conta que havia uma ilha em algum lugar no norte da África onde seus habitantes se alimentavam da flor de lótus (os lotófagos). À causa das propriedades narcóticas da flor de lótus, os habitantes desta ilha viviam em estado de constante sonolência e de amnésia, sucedido que também teria ocorrido com os marinheiros enviados por Ulisses à Ilha. Essa condição permitia ao indivíduo esquecer o passado inglório e recomeçar a vida, ou seja, renascer de novo, associando a flor ao mito da criação. ${ }^{5}$

O fato de a flor de lótus estar presente nas representações das Deusas Asherah e Buddha Tārā, como se verá abaixo, em contextos tão diferentes é instigante. Conforme Pedram Rezania (2011, p. 310), a imagem da flor de lótus, enquanto símbolo de poder criador, migrou do Egito para a Fenícia (Tiro e Sidônia etc.) e dali para a Mesopotâmia e Irã. Essa migração teria acontecido por volta do século VIII a.C. É provável que a associação da flor de lótus com Asherah se deva à relação do atributo da Deusa mãe, enquanto geradora de vida, com o útero.

"Na arte assírio-fenícia e greco-romana, o lótus é utilizado para o enterro e cerimônias fúnebres, indicando a morte e um segundo nascimento, ressurgimento e vida eterna" (Pedram REZANIA, 2011, p. 310). 
Como já mencionado, o caráter sagrado da flor de lótus está relacionado ao ambiente aquático, "porque a água era o antigo símbolo sobre um antigo oceano do qual o mundo foi criado e o lótus flutuante sobre ela era o símbolo do útero" (Pedram REZANIA, 2011, p. 310). Podemos supor, diante disso, uma identificação, associação e assimilação entre lótus e Asherah. Associação tal que Asherah chega a ser identificada como a Deusa lótus, se não a própria personificação do lótus do Nilo (John MCDONALD, 2018, p. 20).

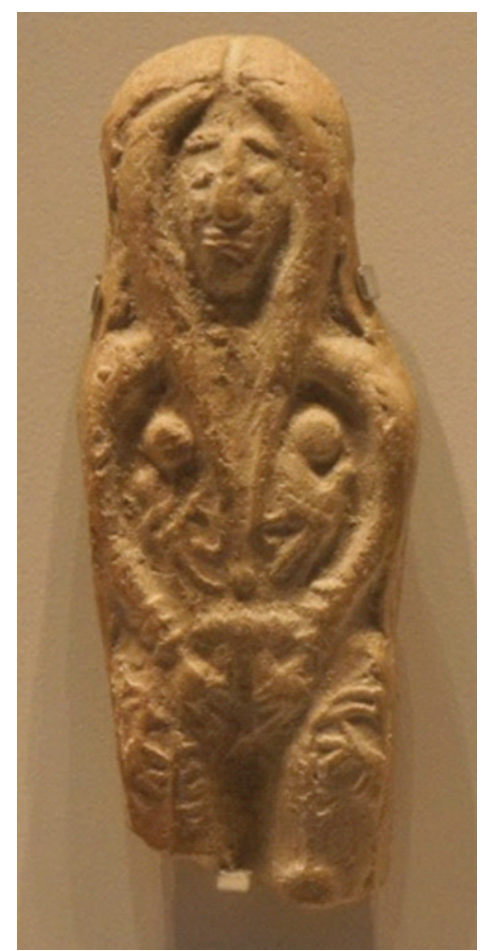

Figura 4- Deusa Asherah dando à luz a gêmeos (Foto: autor. Museu de Israel).

Além das flores de lótus, é evidente o aspecto da fertilidade, da criação, da vida e nutrição nas representações de Asherah. Por isso, as representações da Deusa ilustram uma figura feminina com seios muito fartos, quadris largos e partes íntimas expostas. Todas essas características e atributos estão representados em igual forma em Buddha Tārā, assunto que trataremos a seguir. 


\section{BUDDHA TĀRĀ - CONTEXTO DE SEU CULTO E SUA REPRESENTAÇÃO}

Inicialmente abordaremos as localidades onde foram encontradas as primeiras imagens de Tārā e num segundo momento das características próprias da Deusa e suas semelhanças e associações com Asherah.

\section{OS COMPLEXOS DE CAVERNAS DAS PRIMEIRAS IMAGENS}

Referências à Tãrā em textos budistas são encontradas desde o séc. V d.C., entretanto, as datas atribuídas não são consenso entre os pesquisadores e pesquisadoras. ${ }^{6}$ Há, inclusive, autores que afirmam que Tārā se origina de uma divindade védica chamada Durga (Mallar GHOSH, 1980, p. 17), porém, não há unanimidade, razão pela qual não trataremos desse aspecto.

Acerca da importância que Tārā tem a partir dos sécs. VI, Jae-Eun Shin afirma:

Desde as primeiras imagens de Tārā e evidências textuais é altamente provável que o culto de Tāāā tenha surgido na região oriental e ganhado sua popularidade entre o círculo de budistas antes que ela encontrasse seu caminho para as tradições bramânicas (Jae-Eun SHIN, 2010, p. 16-19). ${ }^{7}$

A primeira imagem de Tārā, conforme pesquisado por Ghosh (Mallar GHOSH, 1980, p. 6), encontra-se no complexo de cavernas de Ellora, mais especificamente na caverna de número 6 . Essas cavernas localizam-se na região de Maharashtra, na Índia, e teriam sido escavadas entre os sécs. VI e VII d.C.

O complexo de cavernas de Ellora, assim como os de Ajanta e Aurangabad (todos situados na região de Maharashtra), representa um achado arqueológico bastante importante para o estudo da tradição budista indiana. Importante, por ser um massivo complexo religioso, com divisão por cavernas, cada uma delas patrocinada por setores

6 O primeiro texto com referência à Tārā é o Ārya-Mañjuśrī-mūla-kalpa, atribuída a sua origem ao séc. $V$ d.C.

7 No original: "From the early images of Tärā and textual evidences it is highly probable that the cult of Tārā arose in eastern region and gained its popularity among the circle of Buddhists before she found her way Into Brahmanical traditions". 
abastados da sociedade indiana. Mas, fundamentalmente importante, pelo valor da compreensão do desenvolvimento humano em todas as suas dimensões para a época, que esse achado arqueológico oferece.

Ellora é um complexo que possui por volta de cem cavernas, entretanto, apenas as de número 1 a 12 são budistas. ${ }^{8}$ Acerca da datação das cavernas, interessa-nos especificamente a número 6 , que, assim como as primeiras imagens de Tārā, também têm sua construção por volta dos sécs. VI e VII d.C.

Mais imagens de Tārā são encontradas, mas em outro complexo de cavernas, cerca de cem quilômetros distante de Ellora, que é o complexo de Ajanta, especificamente na caverna de número 26, que teriam sido esculpidas na pedra, por volta dos sécs. V e VI d.C. O complexo de Ajanta, assim como Ellora, possui um grande centro religioso budista, porém, Ajanta teve suas fases de construção anteriores às de Ellora.

As cavernas do complexo budista começaram a ser escavadas no séc. II a.C., tornando-se tanto locais para a contemplação religiosa quanto morada para os monges que ali viviam e trabalhavam, ao longo de vários séculos. ( $\mathrm{O}$ complexo contém imagens, personagens da tradição budista, bem como monumentos funerários (stupas), símbolos importantes para o Budismo. Cerca de trinta cavernas foram escavadas e esculpidas pelos monges budistas, que eram patrocinados para esse fim. Porém, por motivos políticos e financeiros, houve paralisação e suspensão das obras no ano de 480 , restando algumas cavernas sem qualquer conclusão.

Outro complexo é Aurangabad, que também possui cavernas com locais de visitação religiosa e um centro monástico. Entretanto, dos três, Aurangabad é o menor, possuindo doze cavernas. Sua construção é datada por volta dos sécs. VI e VII d.C. Mais adiante apresentaremos uma das imagens de Tārā da caverna 7 desse complexo.

8 Informação extraída do Ministério da Cultura do Governo Indiano acerca do Levantamento de Informações Arqueológicas da Índia, conforme sítio de internet: http://asi.nic.in/ellora-caves/ (último acesso em 11 de setembro de 2019). 


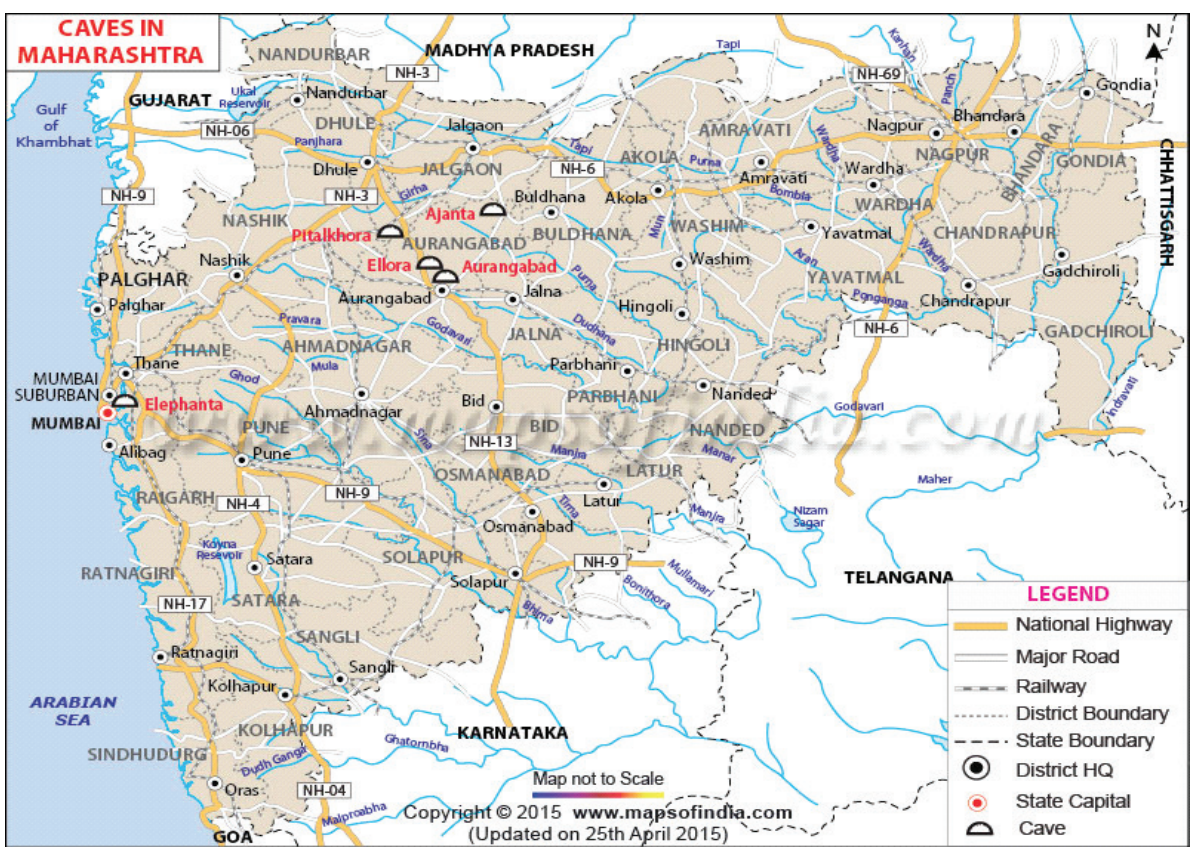

Figura 5 - Mapa da região de Maharashtra, em que podemos ver em vermelho os nomes dos complexos de Ajanta, Ellora e Aurangabad. Fonte: Maps of India - mapsofindia.com

\section{SEMELHANÇAS ENTRE TĀRĀ E ASHERAH}

Utilizaremos duas imagens de Tārā para analisar suas características ao lado das já apresentadas sobre Asherah. As duas imagens selecionadas de Tārā se encontram uma na caverna de número 6 em Ellora, e a outra na caverna de número 7 de Aurangabad.

Acerca da primeira imagem (Figura 6), é importante destacar que há um consenso geral de que se trataria de Tārā. Contudo, há vozes destoantes, como o caso de Geri Hockfield-Malandra (1993, p. 92), que acredita que a imagem não seria de Tārā, mas de outra figura feminina budista, Bhr.kūti, que também teria surgido das lágrimas de Avalokiteśvara. $O$ argumento seria que Tārā representaria o lado compassivo de Avalokiteśvara, enquanto Bhr.kūti o lado ascético.

Em ambas as imagens podemos ver que Buddha Tārā está de pé, com seu corpo inteiramente desnudo, com as partes íntimas expostas, 

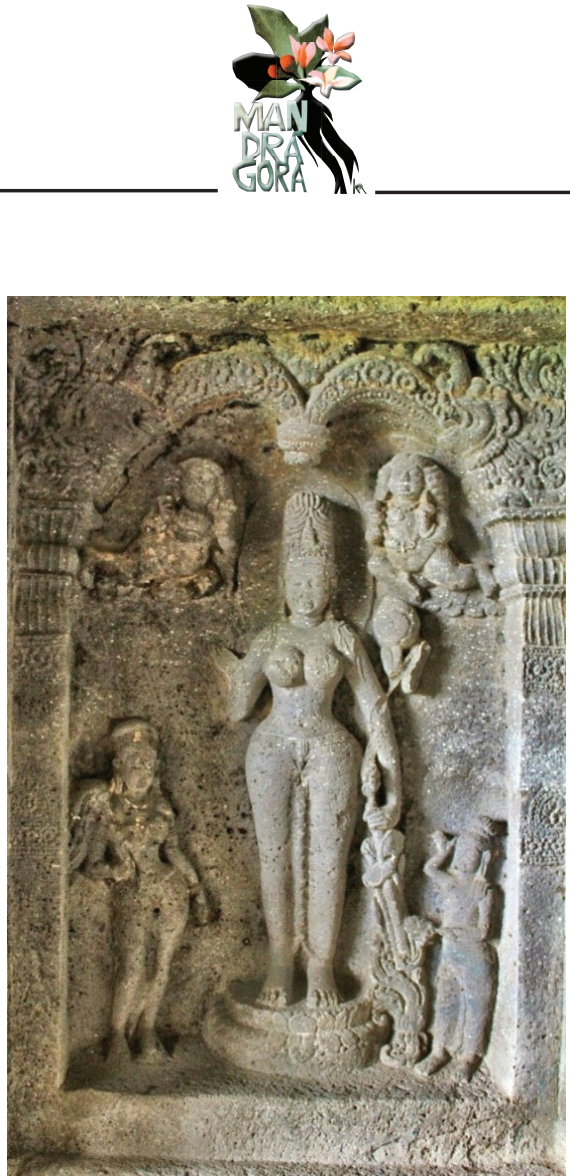

Figura 6 - Escultura de Tārā em pedra, painel na lateral da caverna de $\mathrm{n}^{\circ} 6$ do complexo de Ellora.

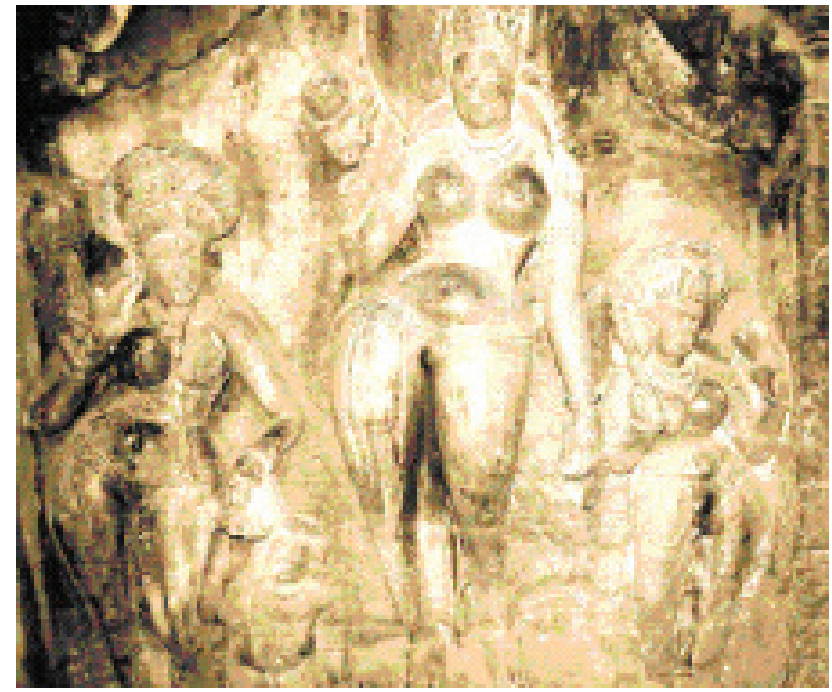

Figura 7 - Gravura de Tārā em pedra, em painel na caverna de $n^{\circ} 7$ do complexo de Aurangabad. Extraída de World Heritage Monuments and Related Edifices in India, Volume 1. 
quadril e seios acentuados. A mão esquerda segura um lótus ${ }^{9}$, que na iconografia de Tārā trata-se de um lótus azul, utpala (Nymphaea caerulea). Temos aqui várias semelhanças com as imagens de Asherah: Assim, como Asherah (cf. figura 3), Tārā está de pé, corpo desnudo, órgãos genitais expostos e avolumados e com flores de lótus nas mãos.

Ao abordar as imagens de Tārā existentes no complexo de Ajanta, cavernas $10 \mathrm{~A}$ e 26, Spink enfatiza a associação da flor de lótus com Tārā e traz elementos relevantes para se entender a evolução da importância de Tārā no cenário budista (Walter M. SPINK, 2005, p. 109):

[...] a mais notável de todas é a de uma figura feminina em pé, segurando uma flor de lótus de caule comprido e de pé sobre um pedestal de lótus duplo no canto inferior da parede esquerda. Esta figura, que não possui nenhuma conexão de composição particular com as outras imagens na parede esquerda, ou da parede de trás, era aparentemente uma imagem independente e que parece representar a bodhisattva feminina Tārāin ${ }^{10}$.

Acerca das representações de Tārā e seus significados, algumas tradições budistas, especialmente as tibetanas, possuem a seguinte narrativa (Min Bahadur SHAKYA, 1994, p. 92 e 93):

Tārā representa todas as atividades iluminadas de todos os Buddhas e, portanto, é chamada de mãe dos Buddhas dos três tempos. Aconteceu em um dia quando Avalokitesvara olhou para a miséria do mundo. Ele derramou lágrimas de seus olhos, por força de sua grande compaixão. As lágrimas se transformaram em uma flor de lótus da qual surgiu uma Tārā branca e outra verde $[\ldots]^{11}$.

9 No masculino designa raiz, caule e flor de lótus, enquanto no feminino designa apenas a flor.

10 No original: "[... ] the most remarkable of all is a standing female figure, holding a long-stemmed lotus and standing on a double lotus pedestal in the lower rear corner of the left wall. This figure, which bears no particular compositional connection with the other images on either the left wall, or the rear wall, was apparently an independent image, and would seem to represent the female bodhisattva, Tārā."

1 No original: "Tārā represents the entire enlightened activities of all Buddhas and hence she is called the mother of the Buddhas of three times. It happened one day when Avalokiteshvara looked at the misery of the world. He shed tears from his eyes out of great compassion. The tears turned into a lotus flower from which appeared a white and green Tārā [... ]". 
Encontramos aqui outra aproximação com Asherah, onde também acontece a correlação do lótus com o aspecto da criação, a Deusa progenitora dos deuses, os filhos de El.

Para Miranda Shaw (2006, p. 310), o nome de Tārā pode ser entendido como "estrela", como "senhora das estrelas" ou ainda como "aquela que salva". Para a pesquisadora, Tārā seria uma estrela guia para os seres sencientes, uma categoria importante para a tradição budista indiana, pois se refere a todo e qualquer ser que possua senciência, não se limitando a seres humanos. De forma que, todo e qualquer ser constituído por cinco agregados, pañcaskandha, que são forma física, rūpa, formações, sam.skāra, ideação, sam.jñā, sensações, vedanā, e consciência, vijñāna, é considerado senciente (Plínio TSAI, 2018, p. 68, 119, 164 e 170). Com isso é possível compreender melhor a dimensão das atividades de Tārā como "aquela que salva".

Para Martin Willson, que organizou uma coletânea de textos acerca de Tárā e os traduziu, ela possuiria o papel de destaque dentro do budismo Mahayana por seu aspecto maternal, como uma Deusa Mãe que resgata do perigo, arquétipo também conhecido no continente europeu, das associações com as divindades Artemis, Ísis e até mesmo com a Virgem Maria (1996, p. 14). Há ainda outro significado importante que o feminino representa para o budismo Mahayana:

Tārā é feminina; e não apenas simbolicamente feminina, segundo o sistema budista do Tantra, pelo qual o homem representa os Meios Habilidosos compassivos e a mulher a Sabedoria do Vazio, mas feminino por escolha própria, a fim de mostrar que o corpo de uma mulher é pelo menos tão bom quanto o de um homem para beneficiar os seres e alcançar o estado da iluminação'12. (Martin WILLSON, 1996, p. 22)

Tārā pode ser considerada, se não a primeira figura do completo despertar feminina e feminista, uma das primeiras junto à tradição budista Mahayana, por força de seu exemplo, ao se dedicar para provar

12 No original: "Now Tārā is female; and not just symbolically female, according to the system of Buddhist Tantra whereby male is compassionate Skillful Means and female is Wisdom of Emptiness, but female by deliberate choice in order to show that a woman's body is at least as good as a man's for benefiting sentient beings and attaining Enlightenment". 
que o corpo feminino é igual ao masculino, e não inferior ${ }^{13}$. Podemos afirmar que este fator, provavelmente, foi determinante na perseguição ao culto de Tārā, assim como com relação ao culto de Asherah.

Claudine Bautze-Picron nos auxilia na interpretação da iconografia budista acerca do papel da maternidade nas representações de Tārā expressas nas diferentes formas de arte budista (Claudine BAUTZE-PICRON, 2010, p. 220):

Ela geralmente é representada de pé ou sentada, com sua mão direita geralmente exibindo o gesto da generosidade e a esquerda segurando o utpala; ela usualmente possui pele de cor verde, como vemos, por exemplo, na capa do livro datado do ano 4 de Gopala IV, ou seja, por volta de 1134, formando um par com Maya, ambas lado a lado, e uma representação dramática da iluminação: na verdade, ambas ficam embaixo de um guarda-chuva e uma árvore asoka $[. . .]^{14}$.

Quem é Maya? Maya é o nome da mãe biológica do Buddha histórico, que morre pouco tempo após o parto. Ela também pode ser chamada de Mahamaya (Plínio TSAI, 2017, p. 79). Tārā, então, pode ser entendida, de acordo com os argumentos de Beautze-Picron, como Maya. Nesse sentido podemos afirmar que há ainda uma relação mais forte referente ao aspecto da compreensão do feminino através da vida e a geração da vida, como chave de compreensão, tanto de Tãrā quanto de Asherah.

Dito de outra forma, temos Maya, como sendo a mãe que trouxe o Buddha Śakyamuni ao mundo em que habitamos, e Tārā, como a mãe que faz nascer e surgir todos os Buddhas, os completos despertos ${ }^{15}$, ambas no papel da maternidade.

13 Além da citação anterior que traz essa perspectiva, o XIV Dalai Lama Tenzin Gyatso, na conferência sobre ação compassiva, em Newport Beach, na Califórnia, no ano de 1989, traz a relação entre a figura de Tārā e sua importância para o movimento feminista dentro do Budismo.

14 No original: "Her most representation shows her standing or seated, the right hand usually displaying the gesture of bestowal, the left one holding the utpala; she is usually green-skinned as we see, for instance, on the book-cover dated in the regnal year 4 of Gopala IV, i.e. around 1134, where she forms a pair with Maya, both flanking a dramatic depiction of the enlightenment: as a matter of fact, both stand below an umbrella and an asoka tree [...]".

15 Tārā, enquanto mãe de todos os Buddhas, cf. Bautze-Picron (2010, p. 221). 
Outro elemento importante trazido à discussão por Bautze-Picron é a árvore asoka (Saraca asoca). A árvore asoka é considerada sagrada na Índia, Nepal e países vizinhos. Daí o motivo narrativo de Maya segurar um galho dessa árvore para dar à luz ao seu filho. Tārā, por sua vez, pode ser representada sob ou ao redor da árvore do completo despertar, ou iluminação, que é a árvore bodhi (Ficus religiosa), bem como sob ou ao redor da árvore asoka, ambas de grande significado para a tradição budista.

O aspecto feminino é tratado no Tantrayana tibetano como a sabedoria do vazio de existência inerente e, então, somente através da combinação entre aspectos feminino e masculino é que pode surgir um Buddha. É um sistema interdependente necessariamente e, se assim não o fosse, não seria possível o resultado e objetivo final, o do completo despertar ou lluminação.

Ainda, sobre as representações dos aspectos femininos e masculinos na formação dos Buddhas, segundo a pesquisa de Claudine Bautze-Picron (2010, p. 222):

Ambos, Tārā e Manjusri, sentam-se e ensinam, demostrando sua função de "pai e mãe" dos Buddhas e Bodhisatvas que os escutam; sua função de dar à luz é simbolizada pelo par Maya / Tārā que está embaixo da árvore asoka [... $]^{16}$.

Esse ideal da maternidade, enquanto voltado ao cuidado com o próximo, outra forma do aspecto feminino, também é atribuído à Tārā no epíteto "mãe de todos os conquistadores" (em sânscrito sarva-jina-mātr.).

Finalmente, com relação à flor de lótus, ela possui muitos significados na cultura budista, por exemplo: ela representa o Caminho Óctuplo do Buddha; ${ }^{17}$ representa o Bodhisattva Avalokiteśvara, pelo

16 No original: "Both, the Tārā and Mañjusri sit and preach, displaying their function of "father and mother" of the Buddhas and Bodhisattvas who listen to them; their function of giving birth is symbolized by the pair Maya / Tărā standing below the asoka tree [...]".

17 O Caminho Óctuplo do Buddha é ensinado dentro do contexto do Sutra das Quatro Verdades Superiores, e esse caminho é o que levaria para fora dos sofrimentos do samsara, sendo os oito: entendimento correto, pensamento correto, linguagem correta, ação correta, modo de vida correto, esforço correto, atenção plena correta e meditação correta (Plínio TSAI, 2017, p. 30 e 31). 
fato de segurar em sua mão uma flor de lótus, sendo atribuído a ele o título de Padmapān.i (em sânscrito), ou aquele que segura um lótus; e representa a saída do sam.sāra, do ciclo de sofrimentos aprisionador.

Enfim, apesar das diferentes dimensões que com o tempo foram sendo adquiridas ou atribuídas à Tārā em diferentes ambientes, é facilmente perceptível a ampla semelhança das características das duas Deusas, Tārā e Asherah.

\section{CONSIDERAÇÕES FINAIS}

Em nossa pesquisa vislumbramos uma estreita relação entre as representações femininas de Asherah e Tārā. Ambas possuem fortes aspectos ligados ao culto da fertilidade, com formas arredondadas, enfatizando exterioridades da fase pós-gestacional, do parto e nutrição da vida que surge. Demonstram a abundância. Tudo se resume no intuito de revelar o caráter sagrado da maternidade, de nenhuma forma um papel subalterno ou secundário.

Outro aspecto bastante em comum em ambas as Deusas é a figura da árvore, cujo provável imaginário está associado à árvore da vida. Em Asherah a representação em alguns tipos de árvores é mais comum, como o terebinto (Elah, que hebraico é o feminino de El), o carvalho, a tamareira e até a macieira. Em geral, esta associação está ligada à fertilidade, ao gerar vida e à nutrição. Em Tārā a associação com alguns tipos de plantas e árvores também acontece, como é o caso da asoka (Saraca asoca), considerada sagrada no oriente, e da bodhi (Ficus religiosa), a árvore do completo despertar ou da iluminação.

No que diz respeito à flor de lótus, que ambas as imagens seguram em suas mãos, também não é possível negar uma correlação entre as duas Deusas. Como visto, a flor de lótus simboliza o útero, a pertença à linhagem divina e o poder da criação, do gerar vida. A própria Tārā, conforme afirma a tradição, teria surgida de lótus, o qual teria nascido de lágrimas de Avalokiteśvara.

Convém mencionar ainda as representações das imagens em pé e sozinhas, sem outra representação ao seu lado. A postura em pé parece indicar a disposição para o agir com rapidez em auxílio das pessoas que suplicam por proteção e cuidado. $O$ fato de serem representadas 
sozinhas, desacompanhadas de uma representação masculina, é instigante, uma vez que as sociedades que geraram essas representações não serem conhecidas historicamente pela igualdade de tratamento entre homens e mulheres. Ou seja, entendemos esta representação como uma atitude insubmissa das Deusas e das/dos que as cultuam a uma divindade masculina e a exigência de um tratamento em pé de igualdade.

Todas estas características das Deuses Asherah e Tārā proporcionaram grande força às mulheres na luta pela sobrevivência. Mas, o culto a elas também foi vítima de muita perseguição e marginalização. Asherah foi excluída do templo de Jerusalém e demonizada pela literatura deuteronomista. O culto à Tārā foi perseguido, imagens foram destruídas e grande parte de sua literatura se perdeu.

Concluímos, então, que de alguma forma o simbolismo das características do feminino retratado em Asherah tenha sido levado até outras regiões, chegando à longínqua Índia e regiões adjacentes e, séculos mais tarde, influenciado a iconografia de Tārā. Desconhece-se escritos que tratem do assunto, de forma que, contamos com que esta pesquisa contribua para o início de outros estudos nesse sentido.

\section{REFERÊNCIAS}

ACKERMAN, Susan. Under every green tree: popular religion in the sixth-century Judah. Atlanta: Scholars Press, 1992.

BAUTZE-PICRON, Claudine. The Lady under the tree: A visual pattern from Maya to the Tārā and Avalokiteśvara. In: The Birth of The Buddha. Lumbini: Lumbini Research Institute, 2010.

BINGER, Tilde. Asherah: Goddesses in Ugarit, Israel and the Old Testament. Sheffield: Sheffiel Academic Press, 1997.

DE MATOS, Sue'Hellen Monteiro. As sagradas de Asherah: Culto à Deus no Antigo Israel. Caminhos, v. 17, n. 1. Goiânia: PUC-GO, 2019, p. 352-370.

DEVER, William. Did God have a Wife? Archeology and Folk Religion in Ancient Israel. Cambridge: William B. Eerdman S. Publishing Company, 2005.

DOS SANTOS, Leide Jane Soares. Belit-Nehseti, cartas da Senhora dos Leões ao rei do Egito: EA 273 e EA 274. Caminhando, v. 23, n. 1, p. 137-146, 2018.

GHOSH, Mallar. Development of Buddhist Iconography in Eastern India: A Study of Tara, Prajna of five Tathagatas and Bhrikuti. Munshiram Manoharlal, 1980. 
CORDEIRO, Ana Luísa Alves. Onde estão as Deusas? Asherah, a Deusa proibida, nas linhas e entrelinhas da Bíblia. São Leopoldo: Cebi, 2011.

CROATTO, Severino. A deusa Aserá no antigo Israel. A contribuição epigráfica da arqueologia. Revista de Interpretação Bíblica Latino-Americana (RIBLA), 38. Petrópolis: Vozes, 2002, p. 32-44.

REIMER, Ivoni Richter (org.). Imaginários da divindade. Goiânia: Editora UCG, 2008.

KEEL, Othmar; UEHLINGER, Christoph. Göttinnen, Götter und Gottessymbole. Neue Erkenntnisse zur Religionsgeschichte Kanaans und Israels aufgrund bislang unerschlossener ikonographischer Quellen. Friburgo: Herder, 1992.

NA'AMAN, Nadav; LISSOVSKY, Nurit. Kuntillet 'Ajrud, Sacred Trees and the Asherah. Journal of the Institute of Archaeology of Tel Aviv University. Tel Aviv: Tel Aviv Univesity, 2008, p. 186-208, 2008.

OTTERMANN, Monika. Vida e prazer em abundância: a Deusa-Árvore. In: Mandrágora, n. 11. São Bernardo do Campo: Universidade Metodista de São Paulo, 2005, p. 40-56 OTTERMANN, Monika. “Eu sou tua Anat e Aserá...”. YHWH e Aserá (não só) no Livro de Oséias. In: Profecia e Esperança: um tributo a Milton Schwantes. São Leopoldo: Oikos, 2006, p. 250-258.

OTTERMANN, Monika. A Deusa Inana-Ištar - uma rival de YHWH? Considerações feministas em torno das Deusas-Árvore e do Deus único da Bíblia Hebraica. In: REIMER, Haroldo; SILVA, Valmor da (org.). Hermenêuticas Bíblicas. Contribuições ao I Congresso Brasileiro de Pesquisa Bíblica. Goiânia: Editora UCG e ABIB, 2006, p. 136-147.

HOCKFIELD-MALANDRA, Geri. Unfolding A Mandala: The Buddhist Cave Temples at Ellora. New York: SUNY Press, 1993.

KAEFER, José Ademar. A Bíblia, a arqueologia e a história de Israel e Judá. São Paulo: Paulus, 2015.

KAEFER, José Ademar. Arqueologia das terras da Bíblia. São Paulo: Paulus, 2012.

MAZAR, Amihai. Arqueologia na terra da Bíblia - 10 000-586 a.C. São Paulo: Paulinas, 2003.

MCDONALD, John Andrew. Influences of Egyptian Lotus Symbolism and Ritualistic Practices on Sacral Tree Worship in the Fertile Crescent from 1500 BCE to 200 CE. In: Religions, vol. 9, 2018.

RANEY, Anson. The El-Amarna Correspondence - A new Edition of the Cuneiform Letters from de Site of El-Amarna based on Collations of all Extant Tablets. Leiden-Boston: Brill, 2015.

REZANIA, Pedram. Symbol of lotus in ancient world. In: Life Science Journal, 2011. RÖMER, Thomas. A Origem de Javé - O Deus de Israel e seu nome. São Paulo: Paulus, 2017. 
SHAKYA, Min Bahadur. The Iconography of Nepalese Buddhism. Buddhanet - Buddha Dharma Education Association Inc. em formato e-book: http://www.buddhanet.net/ pdf_file/icon_nepbud_txt.pdf

SHIN, Jae-Eun. Transformation of the Goddess Tārā with Special Reference to the Iconographical Features. In: INDO-KOKO-KENKYU, Studies in South Asian Art and Archaeology Vol. 31, 2010.

SHAW, Miranda. Buddhist Goddesses of India. New Jersey: Princeton University Press, 2006.

SPINK, Walter M. Ajanta History and Development, Vol. 3. Leiden: Brill, 2005.

TRIPATHI, Rama Shankar. History of Ancient India. Delhi: Motilal Barnasidass, 1999.

TSAI, Plínio Marcos. Comentário ao Tratado Tesouro da Realidade Inefável de Vasubandhu. Valinhos: ATG, 2018.

TSAI, Plínio Marcos. Meditações: A Vida do Buddha. Valinhos: ATG, 2017.

WILLSON, Martin. In Praise of Tārā - Songs to the Saviouress. Boston: Wisdom Publications, 1992.

Submetido em: 27-9-2019

Aceito em: 7-4-2020 